\title{
What's in a peck? Using fixed action pattern morphology to identify the motivational basis of abnormal feather-pecking behaviour
}

\author{
L. M. DIXON, I. J. H. DUNCAN \& G. MASON \\ Department of Animal and Poultry Science, University of Guelph, Ontario \\ (Received 7 December 2007; initial acceptance 2 February 2008; \\ final acceptance 12 May 2008; published online 2 July 2008; MS. number: A07-20015R)
}

\begin{abstract}
Like many captive animals, hens, Gallus gallus, used for agricultural production perform abnormal behaviours. They are particularly prone to feather pecking, the severest form of which involves the pecking at and removal of feathers, which can cause bleeding and even stimulate cannibalism. The two main hypothesized explanations for feather pecking concern frustrated motivations to forage or, alternatively, to dustbathe, leading to redirected behaviour in the form of pecks at plumage. Previous work on pigeons has shown that the detailed morphology of pecks involved in drinking and feeding, or in working for food or water, involves motivationally distinct 'fixed action patterns'. We therefore used methods similar to these fixed action pattern studies to quantify the motor patterns involved in foraging and in dustbathing pecks, for comparison to feather pecking. We videoed 60 chickens pecking at a variety of forages and dustbaths, along with novel objects, water and bird models that could be feather pecked. We recorded the durations of the head fixation before the peck, between the head fixation to beak contact with each stimulus and of the whole peck sequence. We used mixed models to assess whether the motivation underlying a peck affected its morphology and whether severe feather pecks resembled or differed from either dustbath or foraging pecks (or even novel-object pecking or drinking). The motor patterns involved in pecks at forages, dustbaths, novel objects and water all varied significantly; importantly, the motor patterns involved in pecking during dustbathing and foraging differed $(P<0.0001$ for all measures). Severe feather pecks proved similar to foraging pecks (NSD: power $>0.95$ ) but different from all other pecks, including dustbathing $(P<0.0001$ for all measures). These results indicate that severe feather pecking derives from frustrated motivations to forage, not to dustbathe. More broadly, they suggest that finely analysing fixed action pattern morphology can help elucidate the motivational bases of puzzling abnormal behaviours in captive animals.
\end{abstract}

(c) 2008 The Association for the Study of Animal Behaviour. Published by Elsevier Ltd. All rights reserved.

Keywords: chicken; dustbathing; feather pecking; fixed action patterns; foraging; Gallus gallus; motivation; welfare

\begin{abstract}
Abnormal Behaviour
When animals are kept under restrictive conditions, they often show abnormal behaviour, with estimates of over 85 million farm, laboratory and zoo animals displaying these behaviour patterns (Mason \& Latham 2004). Behaviour is generally classified as abnormal if it is not seen in a population deemed normal (e.g. in the wild) or if it is
\end{abstract}

Correspondence: L. M. Dixon, Animal Poultry Science, University of Guelph, Box 103, Guelph, ON, Canada N1G 2W1 (email: ldixon@ uoguelph.ca). caused by a known underlying pathology (e.g. brain dysfunction) or if it causes pathology (e.g. skin lesions) (Mason 1991; Garner 2005). Abnormal behaviour often takes the form of stereotyped movements, which are repetitive and fixed in form (Fox 1968), and may indicate poor welfare, as abnormal behaviour patterns are prevalently found in smaller, barren environments that cause other signs of stress (Mason 1991; Mason \& Latham 2004).

The performance of abnormal behaviours under captive conditions often results in reduced welfare or indicates reduced welfare, and as a result, there is great interest in determining their causal factors. Once this is done, the conditions the animals are kept in can be changed, the 
incidence of abnormal behaviours reduced or eliminated and the welfare of the animals improved. As animal use continues to grow, understanding an animal's behaviour becomes extremely important in improving the humananimal relationship (Timberlake 1997). However, there are numerous examples of abnormal behaviour patterns found in captive animals, the underlying motivations of which are still uncertain: for example, belly-nosing in piglets (e.g. Torrey \& Widowski 2006), barbering in rodents (e.g. Garner et al. 2004), crib-biting in horses (e.g. Bachmann et al. 2003), pacing in carnivores (Clubb \& Vickery 2006) and feather pecking in laying hens (e.g. Harlander-Matauschek et al. 2007). Our goal was to use a novel approach to help determine the motivational bases of abnormal behaviour, using feather pecking in laying hens as a model.

\section{Feather Pecking in Laying Hens}

Feather pecking is an extensive problem in the poultry industry, with $77 \%$ of surveyed commercial poultry operations reporting feather-pecking behaviour (HuberEicher \& Sebo 2001); this likely affects a large number of individuals because approximately 5 billion laying hens are used for production worldwide each year (estimated from Stats Canada). Feather pecking involves pecking at and possibly pulling out the feathers of one bird by another (Hoffmeyer 1969). This behaviour can be divided into two categories: gentle feather pecks, by which the feather is nibbled and pecked at but not pulled out, and severe feather pecks, by which the feather is vigorously pulled or removed (McAdie \& Keeling 2002). Severe feather pecking is considered a welfare problem for poultry, because feather removal is painful for the recipient (Gentle \& Hunter 1990) and blood associated with feather loss can lead to cannibalism (Hughes \& Duncan 1972).

Previous hypotheses propose that feather pecking stems from either frustrated dustbathing or frustrated foraging motivation. Both hypotheses suggest, in general terms, that the lack of particulate matter on the floor (in which to dustbathe or forage) leads to the development of feather pecking in birds kept in cages with wire mesh floors (Blokhuis 1986, 1989; Vestergaard \& Lisborg 1993). Both foraging and dustbathing behaviours have a groundpecking component. If there is no natural substrate on the ground to peck at, it is thus hypothesized that the feathers of cagemates are used as a substitute (Blokhuis 1986; Johnsen \& Vestergaard 1996). However, the evidence for either motivational hypothesis is not entirely conclusive, as past studies do not differentiate between dustbathing ground pecks and foraging ground pecks (e.g. HuberEicher \& Wechsler 1997; Savory \& Mann 1999; Bilcik \& Keeling 2000) and instead make assumptions regarding the motivations underlying the pecking behaviour directed at naturalistic flooring substrates. Our aim is to resolve this issue by exploring the potential use of fixed action patterns to unravel the motivational bases of feather pecking in laying hens. If useful, this technique could then be applied to other abnormal behaviours in other species.

\section{Fixed Action Patterns}

Fixed action patterns (FAPs) are unlearned (innate), repetitive movements in response to external stimuli that are relatively unaffected by feedback, influenced by underlying motivation and species-specific (Lorenz \& Tinbergen 1938). They are sometimes referred to as modal action patterns, a term that takes into account individual variations in performance of the behaviour by referring to the most frequent measurement value (mode) shown in the distribution of the behaviour pattern (Barlow 1968). One well-known example of a FAP is egg rolling in the Greylag goose: if an egg rolls out of the nest, the goose uses specific, predictable head and neck movements to roll the egg back into it and will continue these rolling motions even if the egg stimulus is removed (Lorenz \& Tinbergen 1938). More recently studied examples include the head-bob displays of Anole lizards, which are expressed in adult form right from hatching, regardless of whether the animals are raised in the field or in the laboratory (Lovern \& Jenssen 2003), and grooming movements by mice, which contain certain repetitions of head, arm and paw movements that have been categorized into four distinct phases of grooming (Berridge 1990) and which, once started, will continue if feedback from physical contact with the body is prevented (Golani \& Fentress 1985).

The motivation behind a behaviour pattern will influence precisely how the response to a stimulus is performed (Breland \& Breland 1961). Thus, in pigeons, the stereotyped pecks involved in eating and drinking differ because motivation affects FAP morphology (Zweers 1982, 1992). This was further shown in an autoshaping experiment, autoshaping being when the shape, or movements, directed at a predictive stimulus, such as a button or light, resembles the movements elicited by the reward. For example, rats direct social behaviour at another rat whose presence indicates a future food reward, as rats include social aspects in their feeding behaviour (Timberlake 1975). Thus, pigeons conditioned to peck a key for a food or water reward will also direct 'eating' or 'drinking' pecks to the key, respectively, further showing that the motivation behind each movement affects the motor patterns expressed (Jenkins \& Moore 1973). Based on these characteristics, we planned to use FAPs in an attempt to uncover the motivation behind abnormal feather pecking.

In the following experiments, we quantified aspects of pecking morphology during feather pecking, dustbath pecking and foraging pecking. Our aims were to compare the motor patterns of the different types of feather pecks, as well as the motor patterns of feather pecking pecks to dustbathing and foraging pecks. If severe feather pecking stems from frustrated foraging motivation, then feather pecks should resemble foraging pecks, and nothing else; however, if severe feather pecking stems from frustrated dustbathing motivations, then feather pecks should resemble dustbathing pecks and nothing else. Finally if gentle and severe feather pecking stem from different motivations, then gentle feather pecking pecks should be different in morphology from severe feather pecking pecks. 


\section{METHODS}

\section{Animals and Housing}

All chicks were non-beak-trimmed, 1-day old female ISA White Leghorns, received from a commercial hatchery (Bonnie's Hatchery, Elmira, Ontario, Canada); this strain is known to exhibit feather pecking. The chicks, housed 10 to a pen, were randomly distributed between two identical rooms, with 12 pens in each room (i.e. 24 total) at the Arkell Poultry Research Facility (University of Guelph). For these experiments, we needed birds that performed feather pecking. To ensure this and to identify subjects, we kept the birds in a commercial-typical restrictive environment with no access to a dustbath or forages (cf. e.g. El-Lethey et al. 2000; van de Weerd \& Elson 2006). The pens were wooden framed and measured $127 \times 107 \times 60 \mathrm{~cm}$ with wire-grid $(2.5 \times 2.5 \mathrm{~cm})$ sides and a wire-grid $(1 \times 1 \mathrm{~cm})$ floor. Each pen had two automatic drinking cups and two metal 12-inch slide-top feeders. The chicks were fed ad libitum Chick Starter Fine Crumbles, until week 6 of life, and Chicken Grower diet from week 6 thereafter. The lights were kept on a 23:1 h light:dark (LD) cycle for the first 3 days and then switched to LD 10:14 $\mathrm{h}$ for the remainder of the trial. Temperature at chick level started at $33{ }^{\circ} \mathrm{C}$ and was gradually reduced to $20^{\circ} \mathrm{C}$ by the end of 20 weeks. After 4 weeks, we wing-tagged all birds with coloured tags for individual identification. At one end of each pen, we created a triangular test area $(35 \times 35 \times 24 \mathrm{~cm})$ using a sheet of plastic board covered with black cloth to prevent visual contact with other birds.

\section{Stimulus Design}

When choosing and designing appropriate stimuli to be pecked, we wanted to ensure that any potential differences in peck morphology were due to underlying motivation and not any other aspect of the stimulus, such as its shape or material. We also wanted to address the potential problem of pseudoreplication: if only single exemplars from a type of stimulus are used to test hypotheses about the type itself, it is not clear if the results reflect that particular exemplar only or the broader type of stimulus (e.g. Kroodsma et al. 2001). For example, in one study of the responses of voles and mice to owl calls, a single tawny owl call was recorded and played back to test behavioural and hormonal reaction to a perceived predator (Eilam et al. 1999). However, as Kroodsma et al. (2001) points out, only one tawny owl called was used, making it unclear if the effects were due to owls in general or that particular tawny owl recording. Thus, we used two shapes and three materials for each stimulus type, wherever possible.

\section{Peck Stimuli}

Feathered model

Chicken-shaped feathered model. We killed chickens of ages similar to those of the test birds with $\mathrm{CO}_{2}$ and then arranged them into a sitting posture with a marionettelike structure and froze them (as per Millman \& Duncan 2000). During testing, we presented the models to the test birds with their backs exposed and heads facing the wall.

Flat feathered model. We killed chickens and removed their skin, with feathers attached. We then attached this "feather skin" to a wooden block $(10 \times 10 \times 4 \mathrm{~cm})$.

We classified pecks as gentle when the feather was nibbled at and severe when the feather was vigorously pecked and possibly removed (cf. e.g. McAdie \& Keeling 2002).

\section{Forages}

Chicken-shaped forage. We chose a toy American football $(30 \times 15 \times 15 \mathrm{~cm})$ for its resemblance in size and shape to the back and tail area of a chicken. We applied three types of forage to create three different subtypes of stimulus: (1) peanut butter suet (peanut butter was added to suet at a 1 cup suet to $\frac{1}{4}$ cup peanut butter ratio), (2) seeds in suet (seeds were a mix of shelled and unshelled sunflower seeds added in the same ratio as the peanut butter) and (3) cabbage leaves. We spread the suet evenly over the football, whereas we glued the leaves in place with nontoxic glue.

Flat forage. We filled commercial bird-feeder suet holders $(10 \times 10 \times 4 \mathrm{~cm})$ each with one of the three types of substrate as used for the chicken-shaped forage.

\section{Novel object}

Chicken-shaped novel object. We covered footballs identical to those used for the chicken-shaped forage with one of three different materials, tin foil, tissue paper or felt, again to create three different exemplars of novelty.

Flat novel object. We covered flat wooden blocks of the same size as used for the flat feathered model with one of the three materials used for the chicken-shaped novel object.

\section{Dustbath}

We presented dustbaths in large pans $(30 \times 15 \times 6 \mathrm{~cm})$ filled with one of three substrates: peat moss, white sand or grey sand. It was not possible to create a chickenshaped version of this stimulus.

\section{Water}

We provided a clear dish of water $(10 \times 10 \times 4 \mathrm{~cm})$, so the beak was still visible through the side when the bird was drinking. Again, it was not possible to create a chicken-shaped version of this stimulus.

We videorecorded each of the test birds pecking at one exemplar (subtype) of each of the five stimulus types. We recorded all birds pecking at both the chicken-shaped and the flat varieties of each subtype. 


\section{Selection of Subjects}

Observations began when the birds were 5 weeks of age to identify birds performing the most feather pecking. We observed each pen three times for a period of $30 \mathrm{~min}$ (with at least one period between 700 and 1200 hours and one period between 1200 and 1800 hours). We recorded all occurrences of feather pecking and the identity of the bird doing it. We chose the birds performing the highest levels of feather pecking as test subjects. For choice of sample size see Preliminary Trial and Choice of $N$ for Current Experiment.

\section{Data Collection}

The birds selected as test subjects were habituated to the test area for three 20 min sessions over a 4-day period. After habituation, we gave the birds each of the five categories of stimuli to peck at in the test area. We presented each stimulus once to each bird for $30 \mathrm{~min}$, with the order of presentation randomized, and videorecorded the session. From the video recording of each stimulus type for each bird, we recorded the peck measures for 20 pecks at the stimulus. The test birds housed together (two or three test birds per pen) got the same subtype of forage, dustbath and novelty and this subtype was the same for both the chicken-shaped and the flat exemplars. During trials we measured dustbathing pecks only after a dustbathing bout had begun-i.e. the bird was squatting in the dust and kicking dust onto its feathers (Hoffmeyer 1969).

We videorecorded sessions in which the birds were exposed to the stimuli in real time at $60 \mathrm{fps}$ with a Panasonic CCD camera (WV-BL90A), monitor (WVCM110A) and time-lapse VCR (TL 950). Recording at this high speed enabled us to play back pecks frame by frame and determine accurate durations of the peck morphology with little variation within measures.

\section{Peck Measures}

The following measures of peck morphology used in this experiment were based on previous studies of both pigeons and poultry that quantified various aspects of pecking and compared pecks with different motivational bases (e.g. pigeons: Jenkins \& Moore 1973; Goodale 1983; poultry: Dixon 2008).

(1) Duration of head fixation: the length of time that the head is kept still before the peck.

(2) Duration from fixation to contact: duration from the end of head fixation to beak contact with the stimulus.

(3) Duration of the whole peck: time from no fixation (head movement), through the peck, back to no head movement.

\section{Preliminary Trial and Choice of $\mathrm{N}$ for Current Experiment}

We used data from a preliminary study to calculate the sample size with a power high enough to make type 2 errors unlikely. Increasing the power of a test increases the probability of correctly finding no significant difference between treatments (cf. e.g. Moore \& McCabe 1999). We aimed for a power of $95 \%$, giving us only a $5 \%$ chance of mistakenly finding no difference where one actually exists.

The preliminary study used methods similar to those of the current study, described above. At 5 weeks, the 10 birds performing the most feather pecking were selected. Starting at week 6 , the birds were individually videorecorded for 30-min sessions while pecking at the feathered model, presented both with its back and with its head to the test subjects, and two types of forages. Each of the 10 birds was videorecorded pecking each of the above stimuli. From the video recording of each stimulus for each bird, the peck measures for 20 pecks at the stimulus were recorded. For the pecks at the backs of the feathered models, the type of feather peck, gentle or severe, was also recorded. These results were used to determine the smallest differences between the means of pecks that were not significantly (nor biologically) different from one another (pecks at the two types of forage; $P>0.05$ ) and pecks that were significantly different (pecks at the back and head of the feathered model; $P<0.05$ ), and these differences were used to calculate sample sizes using the techniques of Berndtson (1991). From these preliminary/pilot data, we calculated the smallest difference between means to be $7 \%$ (compared to differences between the means of 10$30 \%$ in the pigeon literature, e.g. Goodale 1983) and that a sample size of 60 birds was needed for the current experiment to have a power of $95 \%$, thus making the potential for type 2 errors unlikely. We chose these 60 subjects from the pool of feather peckers.

\section{Ethical Note}

The use of all animals and methods in this study was approved by the University of Guelph Animal Care Committee, which adheres to Canadian Council on Animal Care guidelines.

\section{Statistical Analyses}

We used a mixed model variance component analysis blocked by subtype of stimulus, with pen nested in subtype, pen as the random factor, and bird nested in pen and subtype as the subject, to determine the effect of peck stimulus on peck measurements (SAS, version 8 ). We normalized the data using natural log transformations where necessary and determined treatment differences using least-square means adjusted by Tukey. We also performed power tests on these results post hoc to ensure that the power level determined in the preliminary study with this sample size (95\%) was maintained throughout the actual study.

\section{RESULTS}

\section{Chicken-Shaped versus Flat Stimuli}

There were no significant differences between the chicken-shaped and the flat versions of any stimulus for 
Table 1. Comparison of the chicken-shaped and flat varieties of stimuli

\begin{tabular}{|c|c|c|c|}
\hline & Duration (s) & Contact (s) & Head fixation (s) \\
\hline Chicken-shaped & $0.176 \pm 0.0025$ & $0.0751 \pm 0.0015$ & $0.165 \pm 0.0045$ \\
\hline Flat & $0.175 \pm 0.003$ & $0.0746 \pm 0.0015$ & $0.169 \pm 0.005$ \\
\hline$F_{1,190}$ & 0.47 & 0.71 & 1.73 \\
\hline$P$ & 0.4941, NS & $0.4017, \mathrm{NS}$ & $0.1797, \mathrm{NS}$ \\
\hline
\end{tabular}

any of the peck motor pattern measures (see Table 1 and Fig. 1). Because of this, we could safely assume that the properties of dustbathing, feather pecking and other pecks were not mere products of the stimulus shape involved, but really did reflect motivational state. The same held for the different materials/subtypes used (e.g. the different substrates offered as dustbaths, etc.) - see below.

\section{Foraging versus Dustbathing and Other Types of Pecks}

Pecks at the dustbaths, forages, novel objects and water all significantly differed from one another in terms of peck duration $\left(\mathrm{F}_{4,129}=19219.8, P<0.0001\right)$. In contrast, the subtypes of each dustbath, forage or novel object involved did not matter (Subtype: duration: $F_{6,108}=2.00$, $P=0.0916$; contact: $F_{6,108}=1.92, P=0.085$; head fixation: $F_{6,108}=0.58, P=0.7495$; see Fig. 1$)$. Thus the motivation behind the peck-not the exact subtype of substrate involved-significantly affected at least this aspect of peck morphology. Somewhat similar findings emerged for the other two measures of peck morphology, but contact duration could not discriminate between dustbathing and novel object pecks (dustbathing versus novel object: $t_{128}=2.37, P=0.1305$; peck stimuli: $\left.F_{4,129}=612.24, P<0.0001\right)$, whereas head fixation could not discriminate between foraging and novel object pecks (forage versus novel object: $t_{128}=0.38, P=0.9955$; peck stimuli: $\left.F_{4,129}=106.97, P<0.0001\right)$. However, even for these measures, where there were significant differences between motivationally distinct types of stimulus, the subtype (e.g. forage subtype, dustbath subtype) had no effect (see Table 2 for means $\pm \mathrm{SE}$ ).

\section{Feather Pecks: Gentle versus Severe}

Gentle and severe feather pecks had different morphologies. Severe feather pecks took longer to perform $\left(F_{1,119}=757.25, P<0.0001\right)$, took longer before contacting the stimulus $\left(F_{1,119}=52.21, P<0.0001\right)$ and involved a longer head fixation $\left(F_{1,119}=12.99, P=0.0005\right)$ than gentle feather pecks (see Tables 2 and 3 for means \pm SE).

\section{Severe feather pecks}

Severe feather pecks were similar to foraging pecks, but differed from all other peck types in duration of the whole peck and time to contact the stimuli (severe feather pecks versus foraging: $\left.t_{128}=-0.18, P=0.9997\right)$. However, for the duration of head fixation, severe feather pecks differed only from dustbathing and drinking pecks, with severe feather pecking taking more time and less time, respectively (severe feather pecks versus foraging: $t_{128}=-0.31$, $P=0.9979 ;$ peck stimuli: $F_{4,129}=106.97, \quad P<0.0001$; Table 2).

\section{Gentle feather pecks}

Gentle feather pecks were different from pecks at the other stimuli for the duration of the whole peck and time to contact stimuli. However, for the duration of head

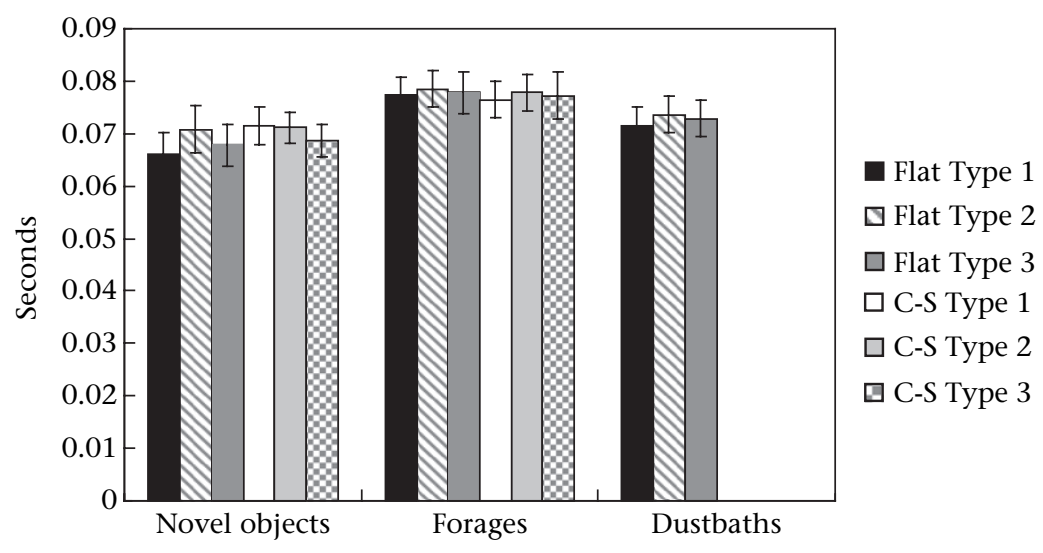

Figure 1. An example of one of the peck measures used (duration of the peck) to examine pecks at the different shapes (flat and chickenshaped) and materials used as the novel object, foraging and dustbathing stimuli measured in seconds ( \pm SE). Each stimulus type was presented in two different shapes and three different materials whenever possible. All subtypes of each stimulus were not significantly different (duration: $\left.F_{6,108}=2.00, P=0.0916\right)$, whereas the different types of stimuli were significantly different from one another $\left(F_{4,129}=19219.8, P<0.0001\right)$. C-S: chicken-shaped. 
Table 2. Severe feather pecks compared to the other types of pecks

\begin{tabular}{|lccc|}
\hline & Duration (s) & Contact (s) & Head fixation (s) \\
\hline Severe feather pecks & $0.19 \pm 0.005^{\mathrm{a}}$ & $0.078 \pm 0.003^{\mathrm{a}}$ & $0.17 \pm 0.009^{\mathrm{a}}$ \\
Foraging pecks & $0.19 \pm 0.004^{\mathrm{a}}$ & $0.077 \pm 0.003^{\mathrm{a}}$ & $0.17 \pm 0.008^{\mathrm{a}}$ \\
Dustbathing pecks & $0.14 \pm 0.003^{\mathrm{b}}$ & $0.071 \pm 0.002^{\mathrm{b}}$ & $0.14 \pm 0.006^{\mathrm{b}}$ \\
Novel object pecks & $0.15 \pm 0.004^{\mathrm{c}}$ & $0.07 \pm 0.002^{\mathrm{b}}$ & $0.16 \pm 0.008^{\mathrm{a}}$ \\
Water & $0.96 \pm 0.018^{\mathrm{d}}$ & $0.12 \pm 0.004^{\mathrm{c}}$ & $0.22 \pm 0.01^{\mathrm{c}}$ \\
$F_{4,129}$ & 19219.8 & 612.24 & 106.97 \\
$P$ & $<0.0001$ & $<0.0001$ & $<0.0001$ \\
\hline
\end{tabular}

Superscripts with different letters indicate significant differences.

fixation, gentle feather pecks were similar to pecks at the forages $\left(t_{138}=1.15, P=0.7819\right)$ and novel objects $\left(t_{138}=-0.89, P=0.9017\right.$; Table 3$)$.

\section{DISCUSSION}

Previous literature had shown that pigeons will give 'feeding' or 'drinking' pecks to buttons they have been trained to peck for a food or water reward, respectively (Jenkins \& Moore 1973), thus showing that motivation affects peck morphology, independent of the target being pecked. Our results for poultry were consistent with this. There were no differences in the peck motor patterns directed at the chicken-shaped and flat versions of each stimulus, nor were there differences in the peck motor patterns directed at the different subtypes within each stimulus (the three forages, the three dustbaths, the three novel objects). In contrast, the motivations involved did affect peck morphology, because peck motor patterns between the different stimulus types were different from each other (forages versus dustbaths versus novel objects versus drinking). Furthermore, between-bird variance for each peck type was very low, as is typical for fixed action patterns (Barlow 1968). Hereafter, therefore, we discuss forages, novel objects, etc., without differentiating their shape or subtype.

Our results showed that severe feather pecks take longer to perform than gentle feather pecks. Severe feather pecks appear very quick to the observer; however, the physical range of head movement is much greater for severe feather pecks than for gentle feather pecks (which involve only a sight movement of the head and neck). Contact duration and the duration of head fixation are also longer. These differences suggest that severe and gentle feather pecks stem from different motivational systems. Furthermore, severe feather pecks are harmful to other birds and thus are a welfare concern, whereas gentle feather pecks are positively associated with preening in chickens; that is, as the incidence of gentle feather pecks increases, so does the amount of preening (Newberry et al. 2007), and gentle feather pecks may be similar to allo-preening found in other species of birds (e.g. zebra finches: Adkins-Regan \& Robinson 1993; Arabian babblers: Pozis-Francois et al. 2004). We therefore consider them separately.

Severe feather pecks proved similar in morphology to foraging pecks, but significantly different from all other types of pecks, including pecks at dustbaths. In contrast, gentle feather pecks were typically different in morphology from other types of pecks. Therefore our data indicate that severe feather pecking stems from a frustrated motivation to forage and not to dustbathe. Gentle feather pecking, in contrast, had a different basis-possibly in rooted preening or in some other motivation not investigated here. Given the opportunity, birds will spend a large amount of their time ground pecking (Dawkins 1989) and the provision of a substrate has been known to decrease feather pecking (e.g. Savory \& Mann 1999; Bilcik \& Keeling 2000; Nicol et al. 2001). Recent work has also shown there is a relationship between feather pecking and feather eating, with high-feather-pecking birds eating more feathers than low-feather-pecking birds (HarlanderMatauschek et al. 2006b). The ingested feathers stimulate feed passage in the digestive tract in a manner similar to insoluble fibre, such as that found in litter substrates (Harlander-Matauschek et al. 2006a). This is all consistent with feather pecking deriving from frustrated foraging.

There is, admittedly, another potential explanation for our results. It is possible that the mere biomechanics of severe feather pecking and foraging are similar in that they both involve picking up an object (feather or food): thus our findings could reflect simply the morphologies of pecks involving pulling and lifting. However, we feel this is unlikely for three reasons. First, birds pecking at the

Table 3. Gentle feather pecks compared to the other types of pecks

\begin{tabular}{|lccc|}
\hline & Duration (s) & Contact (s) & Head fixation (s) \\
\hline Gentle feather pecks & $0.13 \pm 0.006^{\mathrm{a}}$ & $0.065 \pm 0.003^{\mathrm{a}}$ & $0.15 \pm 0.009^{\mathrm{a}}$ \\
Foraging pecks & $0.19 \pm 0.004^{\mathrm{b}}$ & $0.077 \pm 0.003^{\mathrm{b}}$ & $0.17 \pm 0.008^{\mathrm{a}}$ \\
Dustbathing pecks & $0.14 \pm 0.003^{\mathrm{c}}$ & $0.071 \pm 0.002^{\mathrm{c}}$ & $0.14 \pm 0.006^{\mathrm{b}}$ \\
Novel object pecks & $0.15 \pm 0.004^{\mathrm{d}}$ & $0.07 \pm 0.002^{\mathrm{c}}$ & $0.16 \pm 0.008^{\mathrm{a}}$ \\
Water & $0.96 \pm 0.018^{\mathrm{e}}$ & $0.12 \pm 0.004^{\mathrm{d}}$ & $0.22 \pm 0.01^{\mathrm{c}}$ \\
$F_{4,104}$ & 17359 & 446 & 65.12 \\
$P$ & $<0.0001$ & $<0.0001$ & $<0.0001$ \\
\hline
\end{tabular}

Superscripts with different letters indicate significant differences. 
dustbathing substrate sometimes picked particles up and sometimes consumed them. Similarly, birds pecked pieces off the novel objects and at times ate them. Despite this, novel object and dustbathing pecks differed from foraging pecks; and the within- and between-bird variances in peck morphology were still very low for novel object and dustbathing pecks, suggesting that this sporadic 'picking up' did not affect peck morphology. Second, we have shown that subtype of stimulus and shape do not affect motor patterns, suggesting that a motivational, not a biomechanical, explanation is correct. Third, pigeon autoshaping data have shown that the motivation behind a peck influences the motor patterns involved. For example, pigeons trained to peck a button to receive a feed reward will use the same feeding motor patterns on the button as they do when they peck the feed reward itself (Jenkins \& Moore 1973). A definitive test might thus be to require poultry to peck operant buttons to reach different types of reward and look at the morphology of this peck at a completely standardized stimulus. Our prediction is that working for a feather-peck stimulus will involve operant pecks that are spontaneously similar to those elicited when foraging is the reward and different from pecks elicited by the operant for other rewards.

Overall, our data thus concur with recent views that frustrated foraging leads to feather pecking. In terms of poultry welfare in commercial production systems, where processed feed is readily available from a trough, it does not appear that foraging motivation is being satisfactorily fulfilled. The ingestion of high-fibre forages has also been found to aid digestive processes and nutrient digestion, as fibrous material stimulates activity in the gizzard (Hetland et al. 2005). Thus, incorporation of forages into poultry housing, such as straw, hay or silage, is highly encouraged.

The techniques used in this paper provide a model to improve our ability to distinguish specific avian behaviour patterns that, although superficially similar in phenotype, are actually quite distinct. For example, foraging and dustbathing both involve ground pecks, but these pecks are different in their underlying motivation and associated motor patterns. It is possible for a substrate to be used for both foraging and dustbathing, depending on the dominant motivation, but analysing the motor patterns involved in ground pecks is one way to differentiate between two behaviour patterns and thus to reduce the ambiguity of reporting 'ground pecks' in future studies. There are also other potential motor patterns involved in pecking that could be used in future studies to help distinguish between different peck types. For example, if chickens-like pigeons-have two head fixations before pecking (Goodale 1983), not just the one we were able to measure, then this additional measure may be useful when comparing peck morphology. Such additional motor patterns measures would be useful if one was found that gives good statistical power with a smaller sample size. Future work using FAPs could also test the idea that gentle feather pecks are related to preening. Turning to other species, future work with FAPs might help identify, for instance, whether piglet belly-nosing represents infantile udder massage or adult-like rooting (cf. Torrey \& Widowski 2006); whether carnivore pacing represents patrolling, hunting or escape (Clubb \& Vickery 2006); and so on.

These results indicate that severe and gentle feather pecking stem from different behaviour systems. The motor patterns involved in severe feather pecking resemble those of foraging pecks but gentle feather pecks largely differed in morphology from all other pecks measured. This supports the hypothesis that feather pecking stems from a frustrated motivation to forage, not to dustbathe, and emphasizes the need for laying hens to be housed in an environment that allows full expression of foraging behaviour. Finally, this paper shows that analysing fixed action pattern morphology can help determine the motivational bases of abnormal behaviour in captive animals.

\section{Acknowledgments}

This research was supported by a grant from the Ontario Ministry of Agriculture, Food and Rural Affairs. G.J.M. was supported by an NSERC Canada Research Chair. Thanks to the Arkell Poultry Research Staff for help with the models and thanks to the anonymous referees for their helpful comments on the manuscript.

\section{References}

Adkins-Regan, E. \& Robinson, T. M. 1993. Sex differences in aggressive behavior in zebra finches (Poephila guttata). Journal of Comparative Psychology, 107, 223-229.

Bachmann, I., Audige, L. \& Stauffacher, M. 2003. Risk factors associated with behavioural disorders of crib-biting, weaving and boxwalking in Swiss horses. Equine Veterinary Journal, 35, 158-163.

Barlow, G. W. 1968. Ethological units of behavior. In: The Central Nervous System and Fish Behavior (Ed. by D. Ingle), pp. 217237. Chicago: University of Chicago Press.

Berndtson, W. E. 1991. A simple, rapid and reliable method for selecting or assessing the number of replicates for animal experiments. Journal of Animal Science, 69, 67-76.

Berridge, K. C. 1990. Comparative fine-structure of action-rules of form and sequence in the grooming patterns of 6 rodent species. Behaviour, 113, 21-56.

Bilcik, B. \& Keeling, L. J. 2000. Relationship between feather pecking and ground pecking in laying hens and the effect of group size. Applied Animal Behaviour Science, 68, 55-66.

Blokhuis, H. J. 1986. Feather-pecking in poultry: its relation with ground pecking. Applied Animal Behaviour Science, 16, 63-67.

Blokhuis, H. J. 1989. The effect of a sudden change in floor type on pecking behaviour in chicks. Applied Animal Behaviour Science, 22, 65-73.

Breland, K. \& Breland, M. 1961. The mis-behaviour of organisms. American Psychologist, 16, 681-684.

Clubb, R. \& Vickery, S. 2006. Locomotory stereotypies in carnivores: does pacing stem from hunting, ranging or frustrated escape? In: Stereotypic Animal Behaviour. 2nd edn (Ed. by G. Mason \& J. Rushen), pp. 58-85. Cambridge, U.K.: CAB International.

Dawkins, M. S. 1989. Time budgets in red junglefowl as a baseline for the assessment of welfare in domestic fowl. Applied Animal Behaviour Science, 24, 77-80.

Dixon, L. M. 2008. An investigation into the motivation behind abnormal feather pecking behaviour in laying hens. Ph.D. thesis, University of Guelph, Ontario, Canada. 
Eilam, D., Dayan, T., Ben-Eliyahu, S., Schulman, I., Shefer, G. \& Hendrie, C. A. 1999. Differential behavioural and hormonal responses of voles and spiny mice to owl calls. Animal Behaviour, 58, 1085-1093.

El-Lethey, H., Aerni, V., Jungi, T. W. \& Wechsler, B. 2000. Stress and feather pecking in laying hens in relation to housing conditions. British Poultry Science, 41, 22-28.

Fox, M. W. 1968. Abnormal Behavior in Animals. London: W. B. Saunders.

Garner, J. P. 2005. Stereotypies and other abnormal repetitive behaviors: potential impact on validity, reliability, and replicability of scientific outcomes. Institute for Laboratory Animal Research Journal, 46, 113-117.

Garner, J. P., Dufour, B., Gregg, L. E., Weisker, S. M. \& Mench, J. A. 2004. Social and husbandry factors affecting the prevalence and severity of barbering ('whisker trimming') by laboratory mice. Applied Animal Behaviour Science, 89, 263-282.

Gentle, M. J. \& Hunter, L. N. 1990. Physiological and behavioural responses associated with feather removal in Gallus gallus var domesticus. Research in Veterinary Science, 50, 95-101.

Golani, I. \& Fentress, J. C. 1985. Early ontogeny of face grooming in mice. Developmental Psychobiology, 18, 529-544.

Goodale, M. A. 1983. Visually guided pecking in the pigeon (Columba livia). Brain, Behavior and Evolution, 22, 22-41.

Harlander-Matauschek, A., Baes, C. \& Bessei, W. 2006a. The demand of laying hens for feathers and wood shavings. Applied Animal Behaviour Science, 101, 102-110.

Harlander-Matauschek, A., Piepho, H. P. \& Bessei, W. 2006b. The effect of feather eating on feed passage in laying hens. Poultry Science, 85, 21-25.

Harlander-Matauschek, A., Benda, I., Lavetti, C., Djukic, M. \& Bessei, W. 2007. The relative preferences for wood shavings or feathers in high and low feather pecking birds. Applied Animal Behaviour Science, 107, 78-87.

Hetland, H., Svihus, B. \& Choct, M. 2005. Role of insoluble fiber on gizzard activity in layers. Journal of Applied Poultry Research, 14, 38-46.

Hoffmeyer, I. 1969. Feather pecking in pheasants-an ethological approach to the problem. Danish Review of Game Biology, 6, $1-36$.

Huber-Eicher, B. \& Sebo, F. 2001. The prevalence of feather pecking and development in commercial flocks of laying hens. Applied Animal Behaviour Science, 4, 223-231.

Huber-Eicher, B. \& Wechsler, B. 1997. The effect of foraging material and perch height on feather pecking and feather damage in laying hens. Applied Animal Behaviour Science, 58, 131-141.

Hughes, B. O. \& Duncan, I. J. H. 1972. The influence of strain and environmental factors upon feather pecking and cannibalism in fowls. British Poultry Science, 13, 525-547.

Jenkins, H. M. \& Moore, B. R. 1973. The form of the auto-shaped response with food or water reinforcers. Journal of the Experimental Analysis of Behavior, 20, 163-181.

Johnsen, P. F. \& Vestergaard, K. S. 1996. Dustbathing and pecking behaviour in chicks from a high and a low feather pecking line of laying hens. Applied Animal Behaviour Science, 49, 237-246.
Kroodsma, D. E., Byers, B. E., Goodale, E., Johnson, S. \& Liu, W. C. 2001. Pseudoreplication in playback experiments, revisited a decade later. Animal Behaviour, 61, 1029-1033.

Lorenz, K. \& Tinbergen, N. 1938. Taxis and instinctive behaviour pattern in egg-rolling by the Greylag goose. In: Studies in Animal and Human Behaviour. Vol. 1 (Ed. by K. Lorenz; translated by R. Martin), pp. 316-350. Cambridge, Massachusetts: Harvard University Press.

Lovern, M. B. \& Jenssen, T. A. 2003. Form emergence and fixation of head bobbing displays in the green anole lizard (Anole carolinensis): a reptilian model of signal ontogeny. Journal of Comparative Psychology, 117, 133-141.

McAdie, T. M. \& Keeling, L. J. 2002. The social transmission of feather pecking in laying hens: effects of environment and age. Applied Animal Behaviour Science, 75, 147-159.

Mason, G. J. 1991. Stereotypies: a critical review. Animal Behaviour, 41, 1015-1037.

Mason, G. J. \& Latham, N. R. 2004. Can't stop, won't stop: is stereotypy a reliable animal welfare indicator? Animal Welfare, 13, S57S69.

Millman, S. T. \& Duncan, I. J. H. 2000. Strain differences in aggressiveness of male domestic fowl in response to a male model. Applied Animal Behaviour Science, 66, 217-233.

Moore, D. S. \& McCabe, G. P. 1999. Introduction to the Practice of Statistics. 3rd edn. New York: W. H. Freeman.

Newberry, R. C., Keeling, L., Estevez, I. \& Bilcik, B. 2007. Behaviour when young as a predictor of severe feather pecking in adult laying hens: the redirected foraging hypothesis revisited. Applied Animal Behaviour Science, 107, 262-274.

Nicol, C. J., Lindberg, A. C., Phillips, A. J., Pope, S. J., Wilkins, L. J. \& Green, L. E. 2001. Influence of prior exposure to wood shavings on feather pecking, dustbathing and foraging in adult laying hens. Applied Animal Behaviour Science, 73, 141-155.

Pozis-Francois, O., Zahavi, A. \& Zahavi, A. 2004. Social play in Arabian babblers. Behaviour, 141, 425-450.

Savory, C. J. \& Mann, J. S. 1999. Feather pecking in groups of growing bantams in relation to floor litter substrate and plumage colour. British Poultry Science, 40, 565-572.

Timberlake, W. 1975. Auto-shaping in rats to the presentation of another rat predicting food. Science, 190, 690-692.

Timberlake, W. 1997. An animal-centered, causal-system approach to understanding and control of behavior. Applied Animal Behaviour Science, 53, 107-129.

Torrey, S. \& Widowski, T. M. 2006. Is belly nosing redirected suckling behaviour? Applied Animal Behaviour Science, 101, 288-304.

Vestergaard, K. S. \& Lisborg, L. 1993. A model of feather pecking development which relates to dustbathing in the fowl. Behaviour, 126, 291-308.

van de Weerd, H. A. \& Elson, A. 2006. Rearing factors that influence the propensity for injurious feather pecking in laying hens. World's Poultry Science Journal, 62, 654-664.

Zweers, G. A. 1982. Pecking of the pigeon (Columbia livia I.). Behaviour, 81, 173-230.

Zweers, G. A. 1992. Behavioural mechanisms of avian drinking. Netherlands Journal of Zoology, 42, 60-84. 